\title{
The 2012 phenomenon: Maya calendar, astronomy, and apocalypticism in the worlds of scholarship and global popular culture
}

\author{
John B. Carlson ${ }^{1,2}$ and Mark Van Stone ${ }^{3}$ \\ ${ }^{1}$ Center for Archaeoastronomy, P.O. Box X, College Park, MD 20741-3022, USA \\ ${ }^{2}$ University Honors College, University of Maryland, College Park, MD 20742, USA \\ email: tlaloc@umd.edu \\ ${ }^{3}$ School of Arts \& Communication, Southwestern College, \\ 900 Otay Lakes Road, Chula Vista, CA 91910, USA \\ email: mvanstone@swccd.edu
}

\begin{abstract}
This essay introduces the papers from the specially organized session on the theme 'The 2012 phenomenon: Maya calendar, astronomy, and apocalypticism in the worlds of scholarship and popular culture'. The papers that follow address this topical theme in the contexts of Maya and Western cultures as well as academic and popular cultures.
\end{abstract}

Keywords. Maya calendar, Maya astronomy, 2012 phenomenon, apocalypticism, eschatology

\section{Introduction}

The specially organized session on 'The 2012 phenomenon: Maya calendar, astronomy, and apocaplypticism in the worlds of scholarship and global popular culture' addresses several aspects of the overall 'building bridges between cultures' theme of this symposium. The six presenters and the discussant seek to explore new scholarly connections between archaeoastronomy, ethnoastronomy and Mesoamerican studies; between Maya and 'Western' cosmovisions; and between academic research and popular culture.

December 21, the winter solstice, $2012 \mathrm{CE}$ will mark the completion of one highly significant 5,125-year cycle in the ancient Maya 'Long Count' calendar, the period of 13 Bak'tuns or $13 \times 144,000$ days, exactly. Many details of the elaborate Maya calendar, including this remarkable period, have been studied and rediscovered by scholars in the field for more than a century. The academic study of the complex Mesoamerican calendar systems, and their colonial survivals, are certainly worthy topics for students of astronomy in culture, but within the last twenty year or so, particularly with the advent of the new millennium, knowledge of the Maya 13 Bak'tun Great Cycle has moved out of academia into world popular culture with a myriad of new syncretic, often 'new age' forms, at an exponentially increasing pace. As a result of the internet, world wide web, and forms of social networking such as blogs, knowledge of what was once an esoteric scholarly concern is now being appropriated by new cults and individual religious expressions around the globe. As we are now on the eve of the completion of this grand span of time, studies of this '2012 phenomenon' in popular culture are appropriate, more than ever, for students of our interdiscipline and for presentation at this, the last 'Oxford' International Symposium on Archaeoastronomy before the event, particularly as it is being held in the Americas.

In our estimation, there are fewer than two dozen Mayanists, world-wide, who have actively devoted a significant part of their research to some aspect of the 2012 phenomenon. Most professional Mesoamericanists would probably express some opinion about the 
completion of the Maya 13 Bak'tun Long Count cycle in 2012, when asked by their students or the press to comment, but few have any real knowledge beyond what they learned in general published sources, which is precious little. In addition, there are an increasing number of self-appointed experts on the Maya calendar and '2012' who have flooded the web and 'metaphysical' shelves at bookstores with works that range from sincere, though simplistic and misguided, personal explorations, to pseudo-scholarship and the rants of out-and-out charlatans and exploitational writers trying to cash in on the event. Thirty years ago, there might have been a few such self-published fringe publications circulating to small audiences. Now there are close to 1000 books that may be found on the shelves of small local bookshops as well as on-line megastores. The public cravings for esoteric apocalyptic secrets and millennial visions, ranging from catastrophic Armageddons to the dawning to an enlightened 'New Age', are being fed by a virtual army of these Feathered Snake-oil salesmen as many await the return of the 'Plumed Serpent', Quetzalcoatl - the Maya K'uk'ulkan —on December 21, 2012. Of the multitude of books on '2012' now available, perhaps three or four have any content of credible worth; in regard to television documentaries and movies, that number would probably be zero. It is therefore timely and appropriate for the scholars who have invested their time and done the research to go on record and present their investigations for their colleagues and the general public alike. Archaeoastronomy (including ethnoastronomy), as the study of astronomy (and related subjects) in culture, is inherently multidisciplinary and interdisciplinary, and uniquely constituted to address such research questions.

\section{Background}

The Maya, as we call them today, were and still are a diverse Mesoamerican people living largely in what is now the Yucatan Peninsula, Tabasco, and Chiapas in Mexico, Belize, Guatemala, plus parts of Honduras and El Salvador. They form an ethnic-linguistic group whose origins can be traced back more than 3500 years, and today there are perhaps thirty living Maya languages spoken by several million people. Certainly by the Late Formative Period, ca. 200 BCE, the Maya had formed complex state level societies with the rise of polities ruled by hereditary dynasts who would eventually claim divine status. The Maya are world renowned for having created a full logo-syllabic writing system, and a sophisticated arithmetic (with zero and place notation), astronomy, and a remarkable calendar, as well as complex hierarchical societies that developed advanced agricultural systems and sophisticated long-distance interregional exchange networks.

It was roughly at this time (ca. 200 BCE) that the Maya, or possibly another Formative Mesoamerican people with whom they interacted, created the splendid edifice of the Maya Calendar that included what we call for simplicity the 'Long Count'. This is a count of days - very much like J. J. Scaliger's Julian Day Number (JDN) system used by astronomers and chronologists - projected back to a 'creation' event beginning the present cycle of 13 'Bak'tuns' (or 13 Pik, about 5,125 years) on 11 August 3114 BCE. In one of the two most favored correlations (the 584,283-day 'Goodman, Martínez, Thompson', or GMT, correlation) of their Long Count with our Gregorian calendar, this cycle will end on 21 December 2012 CE, which happens to be the winter solstice in their territory. The correlation of their chronology with ours is not absolutely certain, but most Mayanists currently accept a correlation that would place this ending date on 21 or 23 December 2012 (the latter according to the 'Thompson, Lounsbury', or TL, correlation, also known as GMT+2). However, many of the important discussions of the nature and workings of the ancient Maya calendar do not depend on knowing this correlation, although astronomical considerations obviously do. 
The zenith of Maya civilization was reached in the Late Classic period, ca. 600-900 CE, with an interaction sphere of powerful, competing, often warring city-states that traded and exchanged goods and ideas with other Mesoamerican cultures to the west across the Isthmus of Tehuantepec to the Gulf Coast, Central Mexico, and Oaxaca. A single unified Maya empire never formed. Following the 'Maya Collapse' in the Central Lowlands at the end of the Classic (largely as a result of over-population and environmental degradation with drought as the trigger), Maya culture continued in new forms, but most of the highly sophisticated portions of their calendar and astronomy, including the Long Count, were eventually lost (except perhaps in some extremely limited contexts, such as the Dresden Codex). The last-known dated Maya monument was erected in 909 CE. Following European contact and the Spanish conquest, only the Tzolk' in (the sacred, divinatory 260day count) and 'year bearer' systems have survived into the 21st century. The Highland Guatemala Quiché Maya calendar, with its 260-day count and practices of calendrical divination and prophecy, have endured apparently without losing a single day (still in step with the GMT correlation).

Scholarly research on the Maya calendar and the '2012 phenomenon' is now a serious and growing area of academic inquiry, and most of the knowledgeable committed researchers know one another and engage in active exchange. For this topical session, six general areas of research were selected for consideration. Within the limits of presentation time and publication space, most have been addressed by the session's six participants, and their full discussions will ultimately appear in subsequent expanded forms of publication. The research questions are outlined below accompanied by several caveats.

\section{Research questions}

1) What is the relevant scholarship and status of research concerning the Maya calendar and chronology, and the 13 Bak'tun 'Long Count' cycle in particular? Can we know what the ancient Maya, from different times and places, might have expected to happen on the 13.0.0.0.0 4 Ajaw $3 \mathrm{~K}^{\prime}$ ank'in-21/23 December 2012-completion date? This period can also be thought of as 260 prophetic K'atuns (of 7,200 days each), which is yet another important aspect of this Great Cycle. It would certainly have been anticipated as the return of a like-in-kind temporal rite of passage. As a generalization, we understand that all Mesoamerican peoples experienced time as a complex interwoven tapestry of repeating cycles - where at least the personified animate forces influencing 'history' would repeat, if not history itself - with the same gods inaugurated to preside over the events taking place in the Underworld, on the Earth's surface, and in the Sky. These questions of what they might have anticipated relate not only to the Maya calendrical cycles and cosmologies themselves, then and now, but also to those of other Mesoamerican peoples with whom they interacted. Can we also learn more about the Maya from appropriate cross-cultural comparative studies?

2) The 13 Bak'tun Long Count cycle is almost certainly a 'purely' calendrical creation, but claims have been made or asserted in regard to astronomical events at both the beginning and end of the count, depending on the correlation. For example, the start of the cycle on 11 or 13 August 3114 BCE correlates with a solar zenith passage at some latitude in the Maya region and, of course, 21 December 2012 CE (GMT) at the completion, is the winter solstice. Also at this time, the sun will be crossing the Galactic plane and so-called 'Dark Rift' near the coordinates for the Galactic Center, although the latter could not have been known to the ancients as we understand them in academic Maya studies. Is this coincidence, or could these astronomical aspects have been designed into the Long Count when it was created more than 2000 years ago by the Maya or by some other non-Maya (possibly proto-Mixe-Zoquean-speaking) Mesoamerican people? At 
that time, could those temporal architects of the whole complex calendar, including the Long Count, have sufficiently accurate knowledge of the lengths of the solar (tropical) and sidereal years? Did they have any knowledge of the precession of the equinoxes and a system of 'zodiacal' asterisms? If not, then did the Maya of the Late Classic Period, a millennium later, have a reasonable knowledge of precession? These questions have been addressed by previous scholars, but the time is particularly ripe now for a serious process of reassessment. Clearly, new research on Maya calendar correlation and chronology questions is critical for these investigations.

3) Based on a growing corpus of new data from inscriptions, studies of the Maya codices, and ethnohistorical documents such as the highly syncretic colonial Maya books of Chilam Balam, researches on Maya (and Mesoamerican) cosmologies and cosmogonies (creation mythologies) are critical to understanding what the ancients might have anticipated for the end of the 13 Bak'tun cycle. What ceremonies and rites of passage might they have planned? How much can we know about their thinking as to what had taken place more than five millennia ago at its beginning in 3114 BCE? In addition to new research on their cosmogonies, we must also explore all sources of Maya 'apocalypticism', eschatology, divination, and prophecy based on new epigraphic sources, the codices, ethnohistorical documents such as the Quiché Maya Popol Vuh, and cross-cultural studies of, for example, the Aztec 'Calendar Stones' and Legend of the Suns. It is clear that the eschatologies of the late Post-Classic Aztec Legend of the Suns and the 17/18th-century Popol Vuh contributed to respected Mayanist Michael Coe's use of such highly charged words as 'Armageddon', with the present universe to be 'annihilated' in the 2012 apocalypse. His publication of these dire 'biblical' interpretations for 2012 in the first (Coe 1966: 149) and all subsequent editions (Coe 2011: 221) of his influential popularization The Maya, planted the 'meme' in global popular culture of a destructive, 'apocalyptic' 2012. Is this interpretation still warranted in light of all of the current evidence? In the scholarly community, as well as contemporary world popular culture, there are arguments that support both views: a world-destroying catastrophe and the dawning of a spiritual 'New Age' ... and just about everything in between.

4) How is the growing global awareness of ' 2012 ' being ignored or embraced by traditional Native American cultures, and by indigenous Maya peoples in particular? A few real contemporary Maya 'day-keepers' and 'shamans' are becoming involved but it is often difficult to separate the authentic Native American responses to these influences from those of the 'plastic shamans' and fraudulent and opportunistic cult leaders that abound. A second set of questions would ask how people of substantial Native American and specifically Maya heritage, but who are no longer active participants in their ancestral indigenous culture, are dealing with the onslaught of these new ideas and belief systems surrounding the 2012 phenomenon. These studies would essentially be the sociology of Maya astronomy and calendar in their various cultural contexts.

5) The study of the history and sociology of the 2012 phenomenon in global popular culture, including the spawning of literally thousands of new-age 'Mayanistic' cults, with an accompanying exponential growth of related web sites and blogs, would be an appropriate direction for archaeoastronomical research. How and when did knowledge of the Maya Long Count cycle and the ending of the period of 13 Bak'tuns (on December 21, 2012) move out of ivory-tower scholarly academic discussion and research into global popular culture? How has this information - or misinformation as the case might be-been syncretized and amalgamated with everything from the Biblical Deluge, to the destruction of the legendary Atlantis, the Old Norse 'Ragnarok' myth, and even extraterrestrial and U.F.O. cults? In fact, it is hard now to find some tradition that has not been added to the mix. 
6) All knowledge of the ancient Maya Long Count and the 13 Bak'tun cycle, as well as the correlation of their calendar with ours, had been lost to the modern world until they were rediscovered by Western scholars beginning in the late 19th century. What is the history of these discoveries in academic Maya studies, and how were they first popularized and introduced to the general public? The parallel process of the decipherment of Maya writing and the transmission of this information to the public, often in highly romantic, idealized contexts, has contributed to the creation of the myth of the highly advanced ancient Maya whose 'calendar was more accurate than ours'. There exist today groups of devotees who believe that the ancient Maya left the Earth in their space ships, and are scheduled to return to Earth in 2012, led by their leader, the legendary Quetzalcoatl/K'uk'ulkan.

These six categories all provide natural interdisciplinary research questions for archaeoastronomers and students of astronomy in culture, and the research will surely continue well beyond the winter solstice 2012, climax and crescendo of popular preoccupation. Each of the seven scholars participating in this session has devoted many years to their specific interdisciplinary researches and brings a different educational background and expertise to the discussion. All of the six primary presenters have addressed some specific questions within the first three research categories outlined above. Everyone has also given some thought to categories (5) and (6), which involve disciplines from the humanities and arts more than the physical sciences and mathematics, but Hoopes and the discussant, Campion, have focused most on the history and cultural trajectories of these ideas in both academic scholarship and popular culture studies. The one lacuna was in the area of research category (4), the dimensions of Native American awareness of and participation in some aspect of the 2012 phenomenon. This is a particularly rich field of investigation, but of the potential participants who where considered and invited, none was able to attend. Several contributions that will address these questions will be solicited for a more extensive publication currently being assembled.

For all of these investigations there are a few vital caveats to bear in mind. We have all been tempted to say, "The Maya thought this" or "the Maya did that". The ancient Maya thought and did great many things not only over time and space, but also certainly within the same polities and enclaves of literate, educated specialists. Whether we think of them as priests or theologians, writers and scribes or historians, astrologers or astronomers and mathematicians, these philosophers thought a great many things from one day to the next, and undoubtedly disputed and debated them as people have done in all civilizations over the ages. Furthermore, almost nothing of the ancient Maya civilization is left to us as far as what they thought and wrote down. Owing to a collapse of their core civilization at the end of the Late Classic, with almost constant warfare and the ravages of an environment hostile to organic materials, as well as the European conquest, we surely know far less than 1\% - arguably less than $1 \%$ of $1 \%$ - of what they wrote about and recorded on paper, wood, and textiles. We have no surviving astronomical ephemerides or primary astronomical records. Today, there are only four known pre-Columbian Maya 'codices', all of which are Post-Classic and are ritual almanacs. They contain applied astronomy, or astrology and calendrical numerology, if you will, not the original work of observational or theoretical astronomers and calendar keepers. Clearly, we should be careful and conservative with our generalizations.

Finally, a word of warning for anyone who is interested in exploring these topics as an amateur or professional far from his field of expertise. Of the hundreds of published 'books' that deal with the 2012 phenomenon by name, perhaps four have some scholarly validity. The rest range from speculative pseudo-scholarship and new-age fantasy to utter rubbish. Caveat emptor. 


\section{Appendix: understanding Maya calendar cycles-a comparison between theirs and ours}

This brief explanation of the Maya calendar is aimed at non-Maya specialists as background for the papers that follow. For a fuller account see Van Stone (2010).

The 'Maya Calendar', like the Gregorian calendar, comprises several cycles, running concurrently. Both calendars combine elements that originated at different times and in different places, and were used for different purposes. To compare, we shall analyze the same date written in both systems.

\subsection{Gregorian calendar}

The Gregorian date Monday, December 29th, 2008 is also the 363rd day of the year, 3 days before New Year's Day, and falls under the sign of Capricorn. Julian Day Number 2454830. It records:

- Monday = A day of the Week, a never-ending cycle of 7 days, named for the seven visible planets: Sun, Moon, Mars, Mercury, Jupiter, Venus, Saturn. (Germanic peoples adopted analogous Norse Gods Tew, Woden, Thor, and Freya; Latin speakers replaced the weekend days with 'Sabbath' and 'Lord's Day'.) This cycle relates neither to astronomical rhythms nor earthly seasons. It is by far the oldest 'calendar', dating at least to 3rd-millennium BC Babylonia.

- December $=$ One in a cycle of 12 named Months. An ancient lunar cycle, adjusted in Classical Antiquity to match a solar year. Originally numbered (Septem, Octo, Novem, Decem $=$ ' $7,8,9,10$ '), later named to honor gods and men.

- 29th = A subcycle of the Months numbering up to 28, 29, 30 or 31 days. Approximately equals a lunar cycle.

- $363 \mathrm{rd}=$ A solar year cycle, numbering its 365 days. This cycle is barely mentioned before the 20th century, but it appears on many desk calendars today.

- $2008 \mathrm{AD} / \mathrm{CE}=$ Count of years since the birth of Christ. The Anno Domini count, devised by Dionysius Exiguus in $525 \mathrm{AD}$, actually erred by a few years (Jesus was actually born between 2 and $6 \mathrm{BC}$ ). Not really a cycle, this Calendar divides history in two. (Christ's birthday was moved by third-century Christians to the Roman solstice festival of Saturnalia. His original birth date may have been in spring lambing season, which is when "shepherds watched their flocks by night". Dionysius fixed the beginning of the Anni Domini on January 1st, knowing it was a week after His 'actual' birth. Significantly, this 'eighth day' is the traditional date of Christ's circumcision: our yearcalendar, in other words, like a Maya ceremony, begins with a penis-bloodletting.)

- 3 days before New Year's Day = Interval or Distance Number between this day and the next significant event.

- Capricorn = From the Zodiac, another cycle of 12 named Months. Likewise an adjustment of lunar cycles to match a solar year. Originated in Babylonian Chaldea in the 1st millennium BC/BCE.

- JDN 2454830 = Count of Days since the (arbitrarily and) scientifically-selected date 1 January, 4713 BC (Julian). Its 'Day One' is the last time when the first day of three cycles (the Indiction cycle of 15 years, the Metonic cycle of 19 years and the Solar cycle of 28 years) coincided. Joseph Scaliger, who invented the JDN in 1583, liked that it preceded written history.

\subsection{Maya calendar}

The Maya date 12.19.15.17.7, 7 Manik' $10 \mathbf{K}^{\prime} \mathbf{a n k}^{\prime}$ in is $\mathbf{1 3}$ days before the end of the 16th tun. It records:

- 12.19.15.17.7 = Long Count (LC): Comparable to our JDN. This number usually consists of five vigesimal digits, separated by dots. During Classic times, these 'digits' were always coefficients to time-period glyphs, i.e. this date represents 12 Bak'tuns + $19 \mathrm{~K}^{\prime}$ atuns +15 Tuns +17 Winals $+7 \mathrm{~K}^{\prime}$ in. A $\mathrm{K}$ ' in is a day, a Winal is a 'month' of 

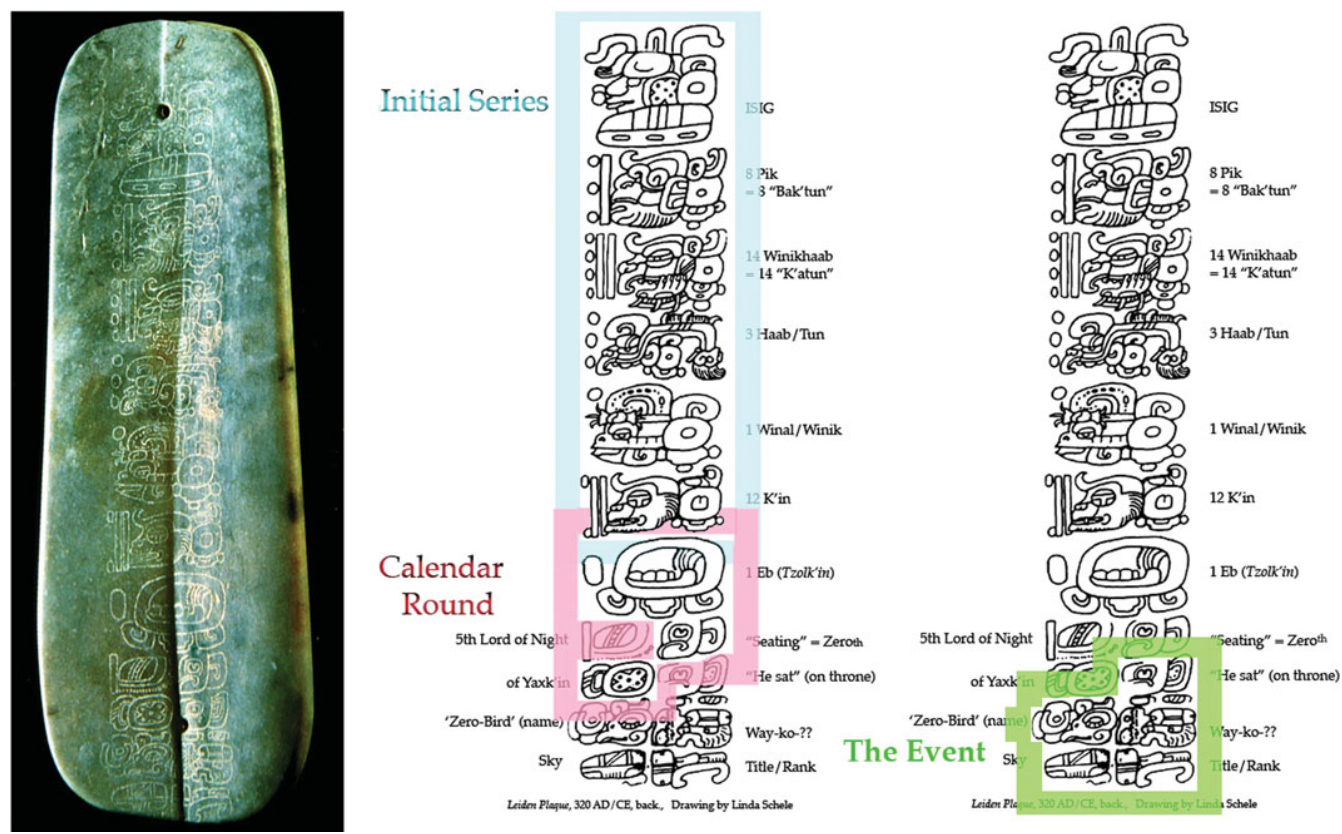

Figure 1. Leiden Plaque, jade, ca. 320 AD. Photograph by Justin Kerr, drawing by Linda Schele. This royal belt-adornment records the accession of a king. Significantly, a great majority of the text records the date of the event: the Long Count date takes up six of the seven large initial glyphs. The seventh is the (260-day) Tzolk in date, followed by three smaller glyphs recording the (9-day) 'Lords of the Night' cycle and finally the 365-day Haab date. The coronation itself (outlined) is squeezed into the last five glyphs, less than $15 \%$ of the total space. This indicates the Mayas' emphasis on fixing an event in time, much more so than in space, or for that matter, than the event itself.

20 days, a Tun is a 'year' of 18 Winals, K'atun means '20 Tuns', and a Bak'tun is 20 K'atuns, or just under 400 years (actually, about $394 \frac{1}{4}$ years) (see Figs 1 \& 2). Instead of years, the Maya counted the days since their 'Creation', the so-called 'Era Date' which falls in 3114 BC. The Epi-Olmec Isthmians (or possibly their Maya neighbors) actually invented the Long Count in about 200 BC, setting their start date some three millennia earlier. The Long Count will reach 13.0.0.0.0 in Dec. 2012.

- 7 = One in a numbered cycle of 13 days, interlocked with Manik' = One day in a named cycle of 20 days. The $13 \times 20$ days of the sacred Tzolk' in ('count of days') is a never-ending cycle of 260 days. Like the Week, it runs independently of any astronomical periods or earthly seasons, though it may relate to (i) the 260-day interval between solar zenith passages at Izapa, (ii) the gestation of a baby in the womb, or (iii) the length of the maize-planting-to-harvest cycle at some altitudes. In any case, the Tzolk' in's names - and numerals - are gods in the Maya pantheon, and like our Week, this 'Calendar' is by far the most ancient and widespread used by all the peoples of Mesoamerica.

- $\mathbf{1 0}=$ One in a numbered cycle of 20 days in the 'month' of $\mathbf{K}^{\prime} \mathbf{a n k}$ 'in $=$ One in a cycle of 19 named 'months' making up the Maya civil calendar, the Haab ('year'), a never-ending cycle of 365 days. The '10th of K'ank'in' works exactly like our '29th of December' except that the Maya 'months' were numerological, not lunar, in origin: 18 of the 'months' were 20 days long, with a shriveled 'month' of 5 days making up the full 365. This cycle, common among the Maya, was rare elsewhere; it played a small role among the Late Preclassic Isthmians and the Postclassic Aztecs. 


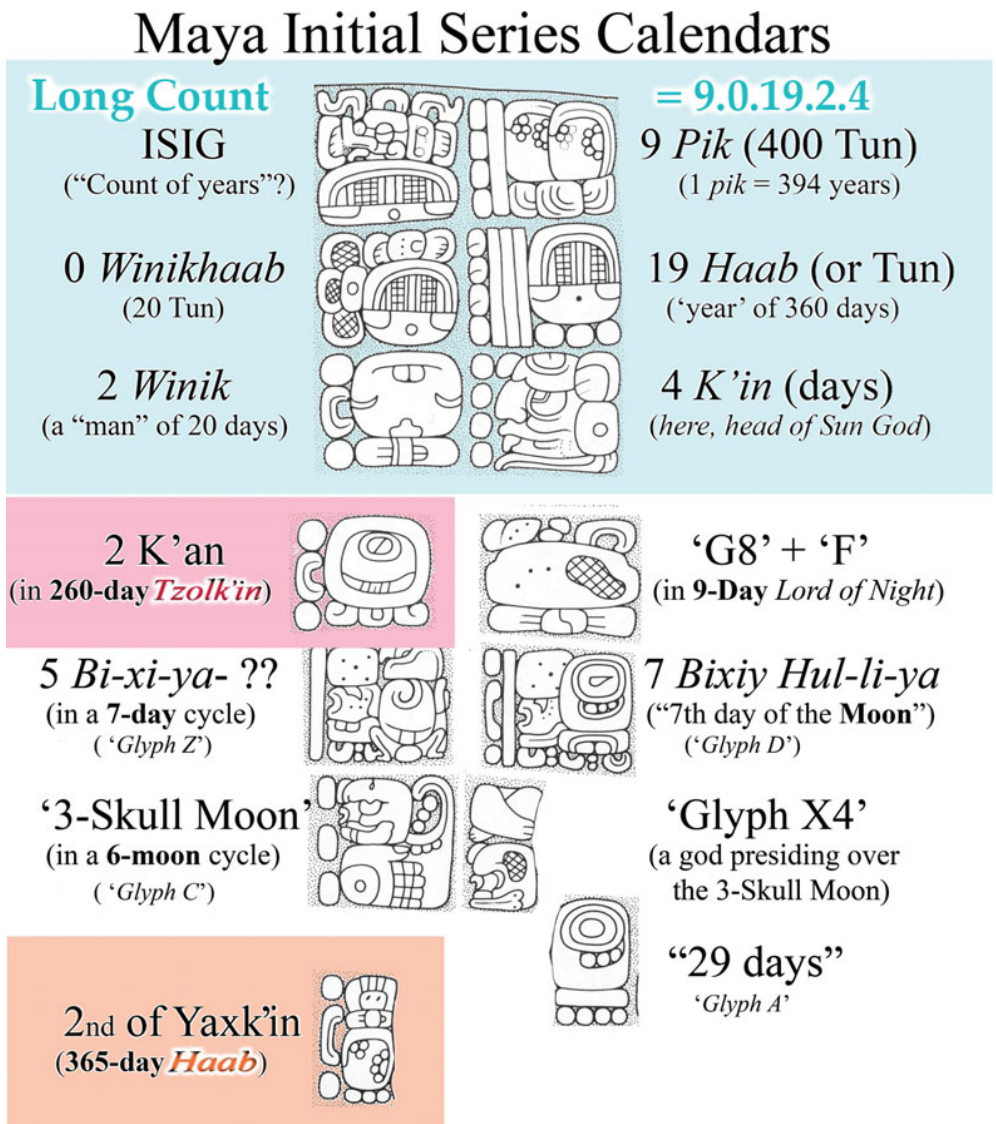

Figure 2. Yaxchilan Lintel 21, Initial Series, ca. 756 AD. Drawing by Ian Graham, Corpus of Maya Hieroglyphic Inscriptions, Fascicle 3, Peabody Museum of Archaeology and Ethnology, Harvard University. This drawing of an Initial Series date highlights the three main Maya calendars: Long Count (top six glyphs), Tzolk' in (immediately after the LC), and Haab (at bottom). The LC fixes a specific date in linear time, while the Tzolk in and Haab together specify a date in the Calendar Round, a 52-year repeating cycle.

- 13 days before the end of the 16th tun = Interval or Distance Number between this day and the next significant event (12.19.16.0.0). 'Round' dates like this, ending in two or three zeroes, were significant anniversaries to the Ancient Maya, just as (for example) 'Y2K' for us today.

- A Maya Initial Series (IS) fixes a monument's commemorations into the fabric of time, sometimes very elaborately. In addition to the usual calendar cycles, an IS cites a nine-day cycle called 'Lords of the Night', specifies the day of the Lunar cycle, and names the Moon in a $3 \times 6$-moon cycle. We occasionally see other 'calendars' here: a 7 -day cycle, an 819 -day numerological cycle $(819=7 \times 9 \times 13)$, and so on. None of these appears outside an IS.

\section{References}

Coe, M. D. 1966, The Maya (First Edition), Praeger, New York.

Coe, M. D. 2011, The Maya (Eighth Edition), Thames \& Hudson, New York.

Van Stone, M. 2010, 2012: Science and Prophecy of the Ancient Maya, Tlacaélel Press, San Diego CA. 